\title{
Optical Tweezers
}

National Cancer Institute

\section{Source}

National Cancer Institute. Optical Tweezers. NCI Thesaurus. Code C62320.

A technique that utilizes light waves to exert minute forces as well as transmit energy to isolate and manipulate nanoparticles. 